\title{
Surface Failure of Commercial and Experimental Restorative Resins
}

\author{
J. M. POWERS, J. C. ROBERTS, and R. G. CRAIG \\ School of Dentistry, The University of Michigan, Ann Arbor, Michigan 48104, USA
}

The mode of surface failure of commercial and experimental restorative resins and composites was evaluated with a single-pass sliding test. The wear of restorative resins and composites is determined by the resistance of the material to penetration and by the mode of deformation during sliding.

Improvement in the wear resistance of restorative resins requires knowledge about the mechanisms of surface failure of these materials during a process such as abrasion. A two-body abrasion test of commercial and experimental restorative resins has shown that the polymer matrix of composite materials wears at a faster rate than that of an unfilled acrylic resin. ${ }^{1}$ Additions of inorganic filler and a silane coupling agent improved the abrasion resistance of the composite polymer dramatically.

The purpose of this investigation was to characterize the surface failure of unfilled diacrylate and acrylic resins and to determine the influence of inorganic filler and a silane coupling agent on the mode of failure of the diacrylate resin.

\section{Materials and Methods}

Two composite resins (A and B), an unfilled resin $(\mathrm{C})$, and experimental formulations of diacrylate resin without filler (D and $E$ ), and filler without silane treatment ( $F$ and G) were evaluated for the mode of surface failure. Product names, batch numbers, and manufacturers are given in $\mathrm{Ta}$ ble 1 .

The resins were mixed according to the manufacturers' instructions and packed into a cylindrical hole $6.4 \mathrm{~mm}$ in diameter and

This investigation was supported by USPHS Grant DE-03416 from the National Institute of Dental Research, National Institutes of Health, Bethesda, Md.

Received for publication April 15, 1975.

Accepted for publication October 6, 1975.
$2.5 \mathrm{~mm}$ in depth) in a cylindrical sample mold $(2.5 \mathrm{~cm}$ in diameter and $1-\mathrm{cm}$ thick) made from acrylic rod. A glass slide was placed on the surface of the mold to provide a smooth surface on the resin sample. The samples were stored at $37 \mathrm{C}$ for 24 hours before testing.

The apparatus used to scratch the surface of a specimen and measure the tangential force has been described in detail elsewhere ${ }^{2,3}$ but consisted of a surface grinder, loading jig, diamond slider, friction transducer, and sample holder. A diamond hemisphere (360 micrometers in diameter) was slid across the surface of the specimens. Fourteen, parallel, one-traversal scratches that resulted from sliding a normal load of 50 to $700 \mathrm{gm}$ were made on each specimen in water. The diamond slider was attached to the loading jig by a strain-gauge transducer that allowed the tangential force to be recorded. The mold containing a specimen was mounted on the table of a surface grinder moving at a speed of $0.025 \mathrm{~cm} / \mathrm{sec}$.

Tangential force and track width data were collected for each run. Track width was measured by a metallograph, with use of a calibrated eyepiece. A scanning electron microscope was used to study wear scars further. Wear scars were classified as to the extent of surface damage according to the following scale: ductile failure, Class 1; tensile cracking, Class 3; and chevron formation, Class 5. Damage intermediate to these was classified as Class 2 or Class 4 , respectively.

A total of 70 samples was tested with the number for each material given in Table 1 . Statistical analysis of the tangential force data was performed with use of a computer program for polynomial regression. 4

Hardness measurements of the unfilled resins $(\mathrm{C}, \mathrm{D}$, and $\mathrm{E})$ were made with a 
TABLE 1

Code, Product Names, Batch Numbers, Manufacturers, and Sample Size of Materials Evaluated

\begin{tabular}{|c|c|c|}
\hline $\begin{array}{c}\text { Code (No. of } \\
\text { Samples Tested) }\end{array}$ & Material Tested & Manufacturer \\
\hline \multicolumn{3}{|c|}{ Composite restorative resins } \\
\hline$A(11)$ & $\begin{array}{l}\text { Adaptic, no. 3358-14a (paste), } \\
\text { no. 3358-14a (catalyst) }\end{array}$ & $\begin{array}{l}\text { Johnson \& Johnson, New } \\
\text { Brunswick, NJ }\end{array}$ \\
\hline B $(9)$ & $\begin{array}{l}\text { Smile, no. } 1176 \text { (paste), no. } \\
\quad 31170 \text { (catalyst) }\end{array}$ & $\begin{array}{l}\text { Kerr Sybron Corp., } \\
\text { Romulus, Mich }\end{array}$ \\
\hline \multicolumn{3}{|l|}{ Unfilled resin } \\
\hline C $(9)$ & $\begin{array}{l}\text { Sevriton, no. LAILD (powder), } \\
\text { no. ML9MM (liquid) }\end{array}$ & $\begin{array}{l}\text { Amalgamated Dental Trade } \\
\text { Distributors Ltd., London, } \\
\text { Eng }\end{array}$ \\
\hline \multicolumn{3}{|c|}{ Experimental formulations } \\
\hline $\mathrm{D}(11)$ & $\begin{array}{l}\text { Adaptic without filler, no. } \\
3358-10 \text { (paste), no. } 3358-10\end{array}$ & Johnson \& Johnson \\
\hline $\mathbf{E}(10)$ & $\begin{array}{l}\text { Smile without filler, no. 38-251-3 } \\
\text { (paste), no. } 31170 \text { (catalyst) }\end{array}$ & Kerr Sybron Corp. \\
\hline F $(10)$ & $\begin{array}{l}\text { Adaptic without silane, no. } \\
\text { 3358-14c (paste), no. 3358-14c } \\
\text { (catalyst) }\end{array}$ & Johnson \& Johnson \\
\hline$G(10)$ & $\begin{array}{l}\text { Smile without silane, no. } 38-251-3 \\
\text { (paste), no. } 41004 \text { (catalyst) }\end{array}$ & Kerr Sybron Corp. \\
\hline
\end{tabular}

Knoop indenter a a load of $250 \mathrm{gm}$. Ten measurements were made on each material and the average was calculated.

\section{Results}

Average values of tangential force and track width vs normal load are shown in Figures 1 and 2, respectively. A polynomial regression curve through zero was fitted to the tangential force vs normal load data. Materials $A, B, D$, and $G$ had linear curves; material $F$, a second degree polynomial curve; and materials $\mathrm{C}$ and $\mathrm{E}$, third degree polynomial curves.

A linear regression curve was fitted to the log of track width vs the log of normal load for each material. The slope and the antilog of the intercept at a load of $1 \mathrm{gm}$ for each curve are given in Table 2 and compared with values calculated from an equation derived from a special case of Hertz's theory of contact between two elastic spheres. ${ }^{b}$ The

a Tukon Tester, ACCO, Wilson Instrument Division, New York, NY.

$b$ The equation used was: $w=1.82(W R)^{1 / 3}\left[\left\{E_{x}\left(1-\nu_{y}^{2}\right\}\right.\right.$ $\left.\left.+E_{y}\left(1-v_{x}^{2}\right)\right\} / E_{x} E_{y}\right]^{1 / 3}$ where $w$ is the track width; $W$ normal load; $R$, the radius of the diamond hemisphere; and $\nu$ and $E$, the Poisson's ratio and Young's modulus of resin $(x)$ and diamond $(y)$, respectively. Values of $E$ and $\nu$ for diamond were $930 \mathrm{GN} /$ meter $^{2}$ and 0.30 , respectively. Valites of $E$ and $\nu$ for materials $A, B$, and $C$ were $16.6 \mathrm{GN} /$ meter $^{2}$ and $0.28,13.5 \mathrm{GN} /$ meter $^{2}$ and 0.28 , and $2.6 G N /$ meter $^{2}$ and 0.36 , respectively.5,0 experimentally observed values of track width were higher at loads greater than $100 \mathrm{gm}$ than were values predicted by elastic behavior.

Scanning electron photomicrographs of wear tracks for material $B$ under a normal load of 200 and $500 \mathrm{gm}$ are shown in Figure $3, \mathrm{~A}$ and $\mathrm{B}$, and are examples of Class 1 failure. Wear tracks on materials $\mathrm{E}$ and $G$ at $500 \mathrm{gm}$ shown in Figure 3, C and D are examples of Class 3 and Class 4 failure, respectively. Between 50 and $700 \mathrm{gm}$, the surface failure of materials $\mathrm{A}, \mathrm{B}$, and $\mathrm{C}$ was Class 1. Over this load range, the failure of materials $F$ and $G$ was Class 4 . The surface failure of materials $D$ and $E$ varied with the normal load; both materials showed Class 1 behavior up to $350 \mathrm{gm}$ in most samples; Class 2 and 3 failures were observed from 400 to $550 \mathrm{gm}$; and for a load range greater than $550 \mathrm{gm}$, the surface failure was Class 4 .

Values of Knoop hardness for the unfilled materials, $\mathrm{C}, \mathrm{D}$, and $\mathrm{E}$ were 18,23 , and $27 \mathrm{~kg}$ per square millimeter, respectively. A standard deviation of $0.5 \mathrm{~kg} / \mathrm{mm}^{2}$ was observed for these data.

\section{Discussion}

The tangential force is a measure of the force required to cause deformation of the resins under the conditions present in this 


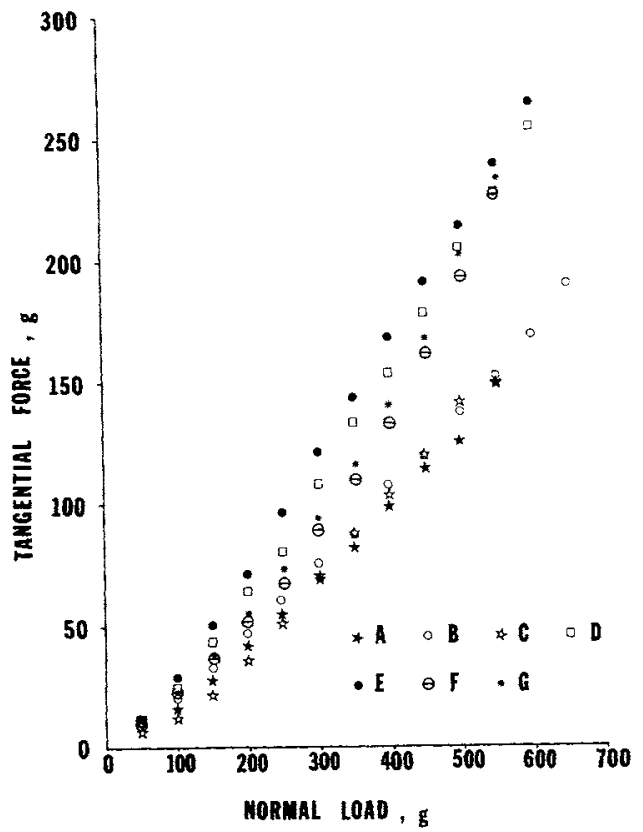

Fig 1.-Tangential force vs normal load for materials A to $\mathrm{G}$.

experiment. Deformation of the composite and experimental formulations was observed as the formation of grooves or cracks in the material or as flaking of the surface (analogous to chevron formation). The force required to deform these resins also depends on the penetration of the slider into the material. At a normal load of $300 \mathrm{gm}$, those resins with larger values of track width (and therefore deeper penetration) also had higher values of tangential force. At the 300 gm load, the surface failure of materials $A$, $\mathrm{B}, \mathrm{D}$, and $\mathrm{E}$ was Class 1. Although materials $F$ and $G$ were classified as Class 4 the extent

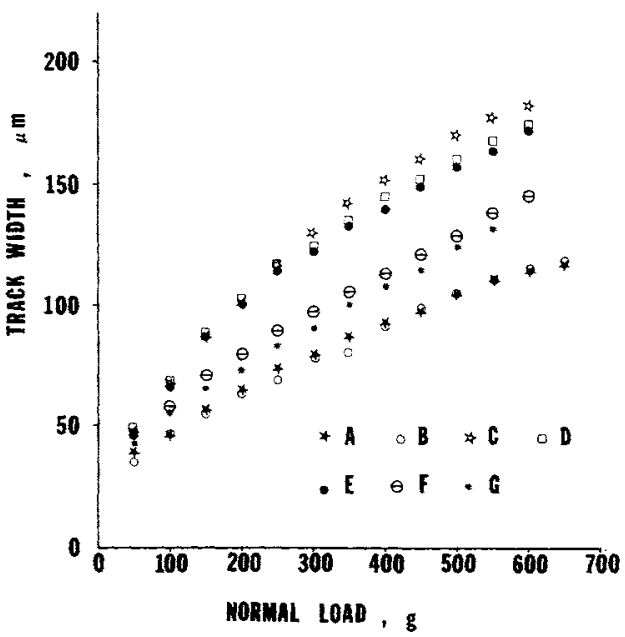

Fig 2.-Track width vs normal load for materials $A$ to $G$.

of flaking was small. At a normal load of $500 \mathrm{gm}$, however, those resins (D, E, F, and $G)$ that had a mode of failure other than groove formation had dramatically higher values of tangential force than materials $A$ and $B$ in which failure type was Class 1.

The diacrylate resins without filler (D and E) had lower values of track width at a load greater than a normal load of $300 \mathrm{gm}$ than the unfilled acrylic resin (C); however, the tangential force values of $\mathrm{D}$ and $\mathrm{E}$ were higher than $C$ at values greater than $100 \mathrm{gm}$. Penetration in these materials was highly dependent on the hardness of the resin, whereas the formation of a wear scar was dependent on the mode of deformation. The Knoop hardness of $\mathrm{C}$ was about $28 \%$ lower than the average hardness of $\mathrm{D}$ and $\mathrm{E}$ and

TABLE 2

Comparison of Track Width Vs Normal load for Actual Data and Data Based on Elastic Behavior

\begin{tabular}{|c|c|c|c|c|}
\hline \multirow[b]{2}{*}{ Material } & \multicolumn{2}{|c|}{ Actual Behavior } & \multicolumn{2}{|c|}{ Elastic Behavior } \\
\hline & $\begin{array}{l}\text { Antilog of Intercept } \\
\text { at a Load of } 1 \mathrm{gm}\end{array}$ & Slope & $\begin{array}{l}\text { Antilog of Intercept } \\
\text { at a Load of } 1 \mathrm{gm}\end{array}$ & Slope \\
\hline A & 6.11 & 0.45 & 8.45 & 0.33 \\
\hline B & 5.40 & 0.47 & 9.00 & 0.33 \\
\hline $\mathrm{C}$ & 5.70 & 0.55 & 15.8 & 0.33 \\
\hline $\mathrm{D}$ & 6.25 & 0.52 & . . & 0.33 \\
\hline $\mathbf{E}$ & 6.65 & 0.51 & $\ldots$ & 0.33 \\
\hline$\vec{F}$ & 6.80 & 0.47 & $\ldots$ & 0.33 \\
\hline G & 6.46 & 0.47 & $\ldots$ & 0.33 \\
\hline
\end{tabular}



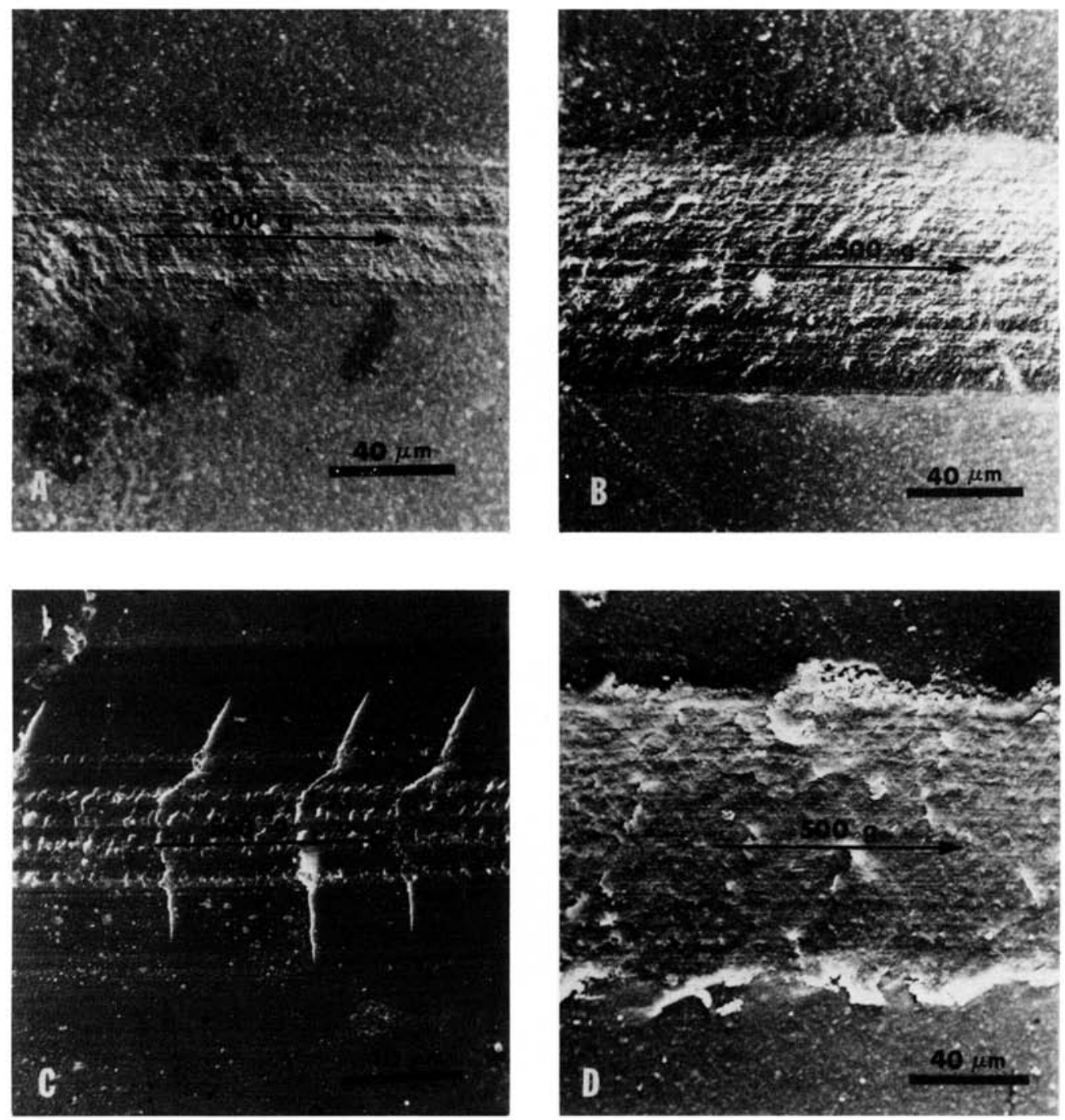

Fig 3.-Scanning electron photomicrographs of wear scars. $A$, material B under 200 gm normal load. $B$, material B under $500 \mathrm{gm}$ normal load. $C$, material $\mathrm{E}$ under $500 \mathrm{gm}$ normal load. $D$, material G under 500 gm normal load.

was less resistant to penetration. Material C, however, is a linear polymer, whereas D and $\mathrm{E}$ are highly cross-linked. The force required to deform a highly cross-linked polymer is apparently greater than that required for a linear polymer.

The addition of nonsilanated filler ( $\mathrm{F}$ and $G)$ to the diacrylate matrix resulted in less penetration and a different mode of surface damage compared with the unfilled materials (D and E). The filler served to stop the formation of the cracks seen in D and E and limited penetration, probably by in- creasing the effective hardness of the material. Addition of silanated filler, as represented by the commercial composite resins (A and B), dramatically improved the resistance to penetration and caused the deformation from sliding to be less severe in nature. These data appear to agree with the overall ranking of the materials as obtained with a silicon carbide abrasion test ${ }^{1}$ although no difference in single-pass parameters between a quartz-filled resin (A) and a resin filled with lithium aluminum silicate and a borosilicate glass (B) was observed. 


\section{Conclusions}

A single-pass test was used to study the surface failure of commercial and experimental restorative resins and composites. The surface failure observed for unfilled diacrylate resins was more severe than that seen for an unfilled acrylic resin. Addition of nonsilanated filler to the diacrylate resins increased the resistance to penetration but did not dramatically change the mode of surface failure. The surface failure of the commercial composite resins, which contain silanated filler, was ductile in mode and the resistance to penetration of the diamond slider was the highest of the materials studied. The wear of restorative resins and composites is determined, therefore, by resistance to penetration as well as mode of deformation during sliding.

\section{References}

I. Powers, J.M.; Allen, L.J.; and Cratg, R.G.: Two-Body Abrasion of Commercial and Experimental Restorative and Coating Resins and an Amalgam, JADA 89: 1118-1122, 1974.

2. Powers, J.M., and Craig, R.G.: Wear of Fluorapatite Single Crystals: I. A Method for Quantitative Evaluation of Wear, $J$ Dent Res 51: 168-176, 1972 .

3. Powers, J.M., and Craig, R.G.: Wear of Fluorapatite Single Crystals: II. Frictional Behavior, J Dent Res 51: 605-610, 1972.

4. Fox, D., and Guire, K.: Midas, 2nd ed (revised), Ann Arbor, Mich: Statistical Research Laboratory, 1974.

5. Dennison, J.B., and Craig, R.G.: Physical Properties and Finished Surface Texture of Composite Restorative Resins, JADA 85: 101 108, 1972.

6. Hall, D.R.; Nakayama, W.T.; Grenoble, D.E.; and KATZ, J.L.: Elastic Constants of Three Representative Dental Cements, $J$ Dent Res 52: 390, 1973. 